\title{
Brusatol Inhibits Laryngeal Cancer Cell Proliferation and Metastasis Via Abrogating JAK2/STAT3 Signaling Mediated Epithelial-Mesenchymal Transition
}

\author{
Jiangtao Zhou ( $\nabla$ zjt881206@sxmu.edu.cn ) \\ Shanxi Medical University https://orcid.org/0000-0002-4975-241X \\ Jing Hou \\ Shanxi Medical University \\ Jun Wang \\ Shanxi Medical University \\ Jiajing Wang \\ Shanxi Medical University \\ Jianping Gao \\ Shanxi Medical University \\ Yun'e Bai \\ Shanxi Medical University
}

Primary research

Keywords: Brusatol, Laryngeal cancer cell, EMT, JAK2/STAT3, Mechanism.

Posted Date: April 12th, 2021

DOl: https://doi.org/10.21203/rs.3.rs-355105/v1

License: (c) (1) This work is licensed under a Creative Commons Attribution 4.0 International License.

Read Full License

Version of Record: A version of this preprint was published at Life Sciences on November 1st, 2021. See the published version at https://doi.org/10.1016/j.Ifs.2021.119907. 


\section{Abstract}

Background: Brusatol (BR) is a principal bioactive quassinoid derived from the Chinese medicinal plant Brucea javanica, which has recently been reported to exert notable cytotoxic effects against numerous cancer cell lines. However, the role that BR played in Laryngeal cancer (LC) is seldom known by the public. In the current study, we have investigated the effects of BR on human laryngeal squamous carcinoma cell (Hep-2) and explored its underlying mechanism both in vitro and in vivo experiments.

Methods: In the present research, cell proliferation, apoptosis, cycle, migration and invasion assays were used to examine the anti-tumor effect of BR on Hep-2 cells. qRT-PCR, immunohistochemistry (IHC) and Western blotting were performed to study the molecular mechanisms of the action. A subcutaneous tumor-bearing model of Balb/c mice with Hep-2 cells of laryngeal carcinoma was established to observe the inhibitory effect of BR on laryngeal cancer cells in vivo.

Results: The results indicated that BR markedly inhibited the viability, migration and invasion of Hep-2 cells in a dose and time-dependent manner, with no significant toxic effect on normal cells BEAS-2B. Also, BR induced cell apoptosis and the cells were blocked in the $S$ phase to suppress cell proliferation. Moreover, the results of IHC showed that BR induction inhibited the protein expression levels of epithelialmesenchymal transition (EMT)-related markers. Mechanistically, western blotting results exhibited that BR could suppress the protein expression of JAK2/STAT3 and their phosphorylation levels. In vivo experiments further confirmed the anti-cancer effect of BR on laryngeal carcinoma cells in vitro, BR suppressed the growth of xenograft laryngeal tumors without apparent toxicity.

Conclusions: Consequently, the present study revealed that the anti-LC effect of BR might be closely relevant to abrogation of JAK2/STAT3 signaling mediated EMT process. BR may be a promising therapeutic candidate for the treatment of laryngeal cancer.

\section{Introduction}

Laryngeal cancer (LC) is the second most widespread malignancy of the upper aerodigestive tract squamous cell carcinoma, which is characterized by hoarseness, sore throat and persistent cough [1,2]. About $95 \%$ of laryngeal carcinoma are diagnosed as laryngeal squamous cell carcinoma (LSCC) [3]. In recent decades, due to excessive tobacco and alcohol consumption, the incidence rate of laryngeal carcinoma has been gradually increased [4]. Currently, surgery and chemotherapy are the most common therapies for the treatment of LC [5]. Nevertheless, chemotherapeutic drugs are always resulted in incomplete clinical efficacy and serious side effects, and surgery frequently lead to the loss of language function $[6,7]$. Therefore, the development of novel and secure therapeutic alternatives is urgently needed. Recently, anti-tumor agent from natural plants is one of alternative treatment options and has been increasingly recognized worldwide.

Brucea javanica, a plant distributed widely throughout Asia, especially in Southern China, has been used in Traditional Chinese Medicine for treating various diseases [8]. The quassinoids are the main 
compounds of Brucea javanica, and largely responsible for its diverse bioactivity [9]. Brusatol (BR, the structure shown in Fig. 1A), an important quassinoid of Brucea javanica, has been rapidly recognized as a potent anticancer agent in the past few decades [10]. The key mechanism for the anticancer activity of BR is suppression of protein synthesis. Importantly, Recent researches have revealed that diverse protein targets of BR were involved in its anticancer activity [11]. Such as, it has been proved to sensitize numerous cancer cells in vitro and A549 mouse xenografts by uniquely blocking the nuclear factor erythroid 2-related factor 2 (Nrf2) pathway [12]. Intriguingly, STAT3 was postulated to be an effector molecule downstream of Nrf2 [13]. As is well-known, JAK2/STAT3 is a crucial signaling pathway involved in cell proliferation, apoptosis, angiogenesis, migration, invasion and metastasis, and has a significant influence on the occurrence and development of tumors [14]. Moreover, it is well known that this signaling pathway regulate epithelial cell-cell adhesion and is intimately associated with the occurrence of EMT in malignant lesions [15]. Currently, it has been discovered that EMT played a key role in the early tumor metastasis, which can render tumor cell with migration and invasion capacities as well as stem cell characteristics [16]. Meanwhile, previous studied has demonstrated that BR could effectively inhibit tumor cell invasion and sensitize the current first-line chemotherapeutic agents in hepatocellular carcinoma and pancreatic cancer via inhibition of the EMT process $[17,18]$.

Based on the above considerations, our present study is to investigate the potential inhibitory effects of BR in human laryngeal carcinoma Hep-2 cell line from the perspective of EMT process and JAK2/STAT3 signaling pathway, aiming to clarify its underlying molecular mechanism into the anti-LSCC effect of BR.

\section{Materials And Methods}

\section{Reagents and chemicals}

Brusatol (BR, purity $>98 \%$ ) was isolated and purified according to previous method [19]. RPMI-1640 culture medium and penicillin-streptomycin were purchased from Gibco (Grand island, NY, USA). Fetal bovine serum (FBS) was purchased from AusGeneX (Gold Coast, Australia). Primary antibodies against $\beta$-actin, STAT3, p-STAT3, JAK2, p-JAK2, E-cadherin, N-cadherin, vimentin and snail were purchased from Abcam (Cambridge, United Kingdom). All antibodies were diluted with $5 \%$ fat-free milk in Tris-buffered saline with Tween (TBST).

\section{Cell lines and culture}

Human laryngeal squamous carcinoma cell line Hep-2, human esophageal cancer cell line K150 and human ovarian cancer cell line SK-OV-3 were purchased from the China Center for Type Culture Collection and cultured in RPMI-1640 supplemented with $10 \%$ fetal bovine serum (FBS). Human bronchial epithelial cell line BEAS-2B, human hepatoma cell line HepG2, human non-small cell lung cancer cell line A549 and human colorectal cancer cell line Caco-2 (EK-Bioscience, Shanghai) were cultured in DMEM supplemented with $10 \%$ heat-intactived FBS, $1 \%$ streptomycin/penicillin in a humidified atmosphere with $95 \%$ air and $5 \% \mathrm{CO}_{2}$ at $37{ }^{\circ} \mathrm{C}$. 


\section{Cell Counting Kit-8 (CCK8) assay}

Cell viability was determined by CCK-8 analysis. Briefly, cells were seeded into 96 well plates at a density of $5 \times 10^{4}$ cells/well and incubated until $80 \%-90 \%$ adherence. Then, different concentrations of BR $(0,0.1$, $0.2,0.3,0.4,0.45,0.5,0.6,0.8 \mu \mathrm{M}$ ) exposing on Hep-2 and BEAS-2B cells for 24,48 and $72 \mathrm{~h}$. The plates incubated with CCK-8 (Tansgen, Beijing, China) at $37^{\circ} \mathrm{C}$ for $2 \mathrm{~h}$. OD values were measured on an automatic microplate reader (Allsheng, AMR-100, Hang Zhou, China) at $450 \mathrm{~nm}$. The experiment was repeated three times.

\section{Morphological observation}

Hoechst 33258 staining assay (Beyotime Biotechnology, Shanghai, China) was applied to observe the morphological characteristics of apoptosis cells. Shortly, the Hep-2 cells were seeded into 6-well plates at a density of $5 \times 10^{5}$ cells/well and incubated with BR $(0,0.2,0.4,0.6 \mu \mathrm{M})$ for $24 \mathrm{~h}$. Then, cells were fixed with $4 \%$ polyoxymethylene and washed three times with PBS, followed by incubated for 15 mins in the dark with Hoechst $33258(10 \mu \mathrm{g} / \mathrm{mL})$ and washed three times with PBS. The morphology of apoptotic cells was observed under the fluorescence microscopy (DMi8, Leica, Germany). The experiment was repeated three times.

\section{Flow cytometry analysis (FCM)}

\section{Cell cycle assay}

Cells were inoculated into 6-well plates at a density of $1 \times 10^{6}$ cells/well and treated with different concentration of $\mathrm{BR}(0,0.2,0.4,0.6 \mu \mathrm{M})$ for $24 \mathrm{~h}$. For cell cycle assay, cells were washed with PBS, harvested by trypsinization and fixed with $70 \%$ ethanol at $4{ }^{\circ} \mathrm{C}$ for $5 \mathrm{~h}$, then stained with Propidium lodide (PI, Keygen Biotech, China) in dark at $37^{\circ} \mathrm{C}$ for 30 mins. Determination of stained cells was by using FCM (BD Bioscience, USA). The experiment was repeated three times.

\section{Cell apoptosis assay}

Apoptosis was analyzed with the Annexin V-FITC Apoptosis Detection Kit (Keygen Biotech, China) following manufacturer's instructions. Cells were exposed to different $B R(0,0.2,0.4,0.6 \mu \mathrm{M})$ for $24 \mathrm{~h}$.

The treatment cells were harvested with EDTA-free trypsin and washed with cold PBS, then the cells were resuspended in $200 \mu \mathrm{L}$ binding buffer and stained with $5 \mu \mathrm{L}$ Annexin V-FITC and $5 \mu \mathrm{L}$ Propidium lodide in dark for 30 mins. Determination of stained cells was by using FCM within $1 \mathrm{~h}$. Data were analyzed by FlowJo software (Tree Star, OR, USA). The experiment was repeated three times.

\section{Transwell assay}

Transwell assay was applied to evaluate the Hep-2 cells migration and invasion. Briefly, the treatment cells were resuspended with $4 \times 10^{4}$ cells in $200 \mu \mathrm{L}$ serum-free RPMI-1640 and added into the upper chambers of Matrigel-uncoated and -coated transwell inserts (24 plate with $8 \mu \mathrm{m}$ pore diameter, Corning, Inc., Corning, NY, USA). The lower chamber was filled with $200 \mu \mathrm{L}$ RPMI-1640 containing 20\% FBS at 37 
${ }^{\circ} \mathrm{C}$ for $48 \mathrm{~h}$, the cells that had migrated or invaded to the lower chamber were fixed with $4 \%$ paraformaldehyde in PBS buffer and stained with crystal violet $(0.1 \%)$. The cells were observed in a microscope and cells from at least three randomly selected fields were counted. Each concentration was repeated 3 chambers and cells from at least 5 randomly selected fields were counted.

\section{Quantitative Real-Time Polymerase Chain Reaction (qRT- PCR)}

Total RNA was isolated from the prepared cells using TransZol UP reagent (Transgen, Beijing, China), and $1 \mu \mathrm{g}$ of total RNA was reversely transcribed into cDNA using one-step gDNA Removal and cDNA Synthesis Supermix kit (Transgen, Beijing, China) according to the manufacturer's instructions. Next, qRTPCR analyses using Tip green qPCR Supermix in the Light Cycler 96 Real Time PCR System (Roche, Mannheim, Germany). The used primers were purchased from Sangon Biotech Co. Ltd. (Shanghai, China). Table 1 has listed the sequences of primers. Thermal cycling conditions were as follows: $30 \mathrm{~s}$ at $94{ }^{\circ} \mathrm{C}, 40$ cycles of $5 \mathrm{~s}$ at $94^{\circ} \mathrm{C}$ and $30 \mathrm{~s}$ at $60^{\circ} \mathrm{C}$. The fold-change of expression was calculated using the $2^{-\Delta \Delta C t}$ method and normalized by $18 \mathrm{~s}$.

Table 1

Sequences of the primers used in the real-time PCR

\begin{tabular}{|lll|}
\hline Target & Forward primer sequence $\left(\mathbf{5}^{\prime} \mathbf{- 3} \mathbf{3}^{\prime}\right)$ & Reverse primer sequence $\left(\mathbf{5}^{\prime} \mathbf{3}^{\prime} \mathbf{)}\right.$ \\
\hline N8S & GCAATTATTCCCCATGAACG & GGCCTCACTAAACCATCCAA \\
\hline N-cadherin & TTTTGCCCCCAATCCTAAGA & GTCAGAAGCAAGGAAAGTAGCATTA \\
\hline E-cadherin & CTGGGCTGGACCGAGAGA & GAAGGTCAGCAGCTTGAACCA \\
Vimentin & GCCAGGCAAAGCAGGAGTC & AGTGGGTATCAACCAGAGGGAGT \\
Snail & AATCGGAAGCCTAACTACAGCG & GTCCCAGATGAGCATTGGCA \\
JAK2 & ATGTCTTACCTCTTTGCTCAGTGGC & GGTTTGATCGTTTTCTTTGGCTAT \\
STAT3 & CCTGAAGCTGACCCAGGTAG & TTCCAAACTGCATCAATGAATC \\
\hline
\end{tabular}

\section{Immunohistochemistry Analysis (IHC)}

Immunohistochemistry was performed according to our previous method [20]. Briefly, the paraffinembedded cell slices were dipped into xylene and graded ethanol in order to dewax and rehydrate. After antigen retrieval and endogenous peroxidase activity is blocked, the sections were incubated overnight with rabbit Vimentin, E-cadherin, $\mathrm{N}$-cadherin and Snail polyclonal antibody (Abcam, USA) at $4^{\circ} \mathrm{C}$, respectively. After washed three times, the slices were successively subjected to the rest of the process, including incubation with biotin-linked secondary antibody, PBS washing, streptavidin-HRP incubation, $D A B$ staining and hematoxylin counterstaining. Finally, the pictures were captured with the microscope imaging system microscope. The integrated optical density (IOD) and of each photograph was analyzed using Image-Pro Plus 6.0 (Media Cybernetics, Inc., Rockvile, MD, USA). 


\section{Western Blot Analysis}

Cell samples were lysed on ice in RIPA buffer (Servicebio, Hubei, China) containing 1\% PMSF and 1\% phosphorylated inhibitors. The BCA protein assay kit was used to determine the protein concentration and after separation on $10 \%$ SDS-polyacrylamide gel electrophoresis, $20 \mu \mathrm{g}$ of protein was electrically imprinted on PVDF membrane. The immunoblots were then incubated with antibodies to STAT3, pSTAT3, JAK2, p-JAK2 and $\beta$-actin (Abcam, USA) respectively. All intensities of the target protein bands were detected using ChemiDocRS imaging systems and analyzed using Image lab software 6.0 (Bio-Rad Laboratories).

\section{Animal Model}

Male Balb/c mice (weight $25 \pm 2 \mathrm{~g}$ ) were provided by SPF Biotechnology Co., Ltd. (Beijing, China) and maintained under SPF conditions. After a week of adjustable feeding, Hep-2 cells $\left(3 \times 10^{6}\right)$ were injected subcutaneously into the right armpit of the mouse. After the tumor volume reached approximately 100 $\mathrm{mm}^{3}$, randomly divided into four groups $(\mathrm{n}=6)$ : solvent group: mice were injected intraperitoneally (i.p.) with solvent every two days. Positive control group (cisplatin group): mice were injected with $3 \mathrm{mg} / \mathrm{kg}$ cisplatin (Cis) every three days platinum. BR groups: mice were given $1.0 \mathrm{mg} / \mathrm{kg}$ or $2.0 \mathrm{mg} / \mathrm{kg} \mathrm{BR}$ by gavage every two days. After 20 days of treatment, the mice were euthanized by intraperitoneal injection of sodium pentobarbital once $(200 \mathrm{mg} / \mathrm{kg})$ and the tumor tissues were extracted and weighed. All animal experiments were conducted in accordance with institutional guidelines and regulations, and all animal studies were approved by the Institute of Animal Care and Use of Shanxi Medical University.

\section{HE staining}

The tissue sections were dewaxed, then dyed with hematoxylin and Eosin (H\&E), rinsed with distilled water, dehydrated with gradient anhydrous ethanol, transparently treated with xylene, and then sealed with neutral gum. The sections were observed and photographed under a Nikon ECLIPSE E100 optical microscope (Nikon, Tokyo, Japan).

\section{Statistical Analysis}

All experiments were repeated at least three times. Statistical analyses were performed using SPSS software (version 26.0, IBM, New York, USA) and GraphPad Prism version 6.0 (GraphPad software, San Diego, CA, USA). All values were presented as mean \pm SD. One-way ANOVA analysis was performed for comparison of multiple means. Statistical significance was set at $P<0.05$.

\section{Results}

\section{The inhibition effects of BR on proliferation of cancer cells}

Human cancer cell lines of six different histotypes were used to investigate the anti-proliferation activities of BR by Cell Counting Kit-8 (CCK-8) assay for $24 \mathrm{~h}$, and the results indicated that the inhibitory effect 
was obviously different between different cancer cell lines. Intriguingly, we found that the human laryngeal carcinoma cell line Hep-2 was the most sensitive to the treatment of BR, with an IC50 value of

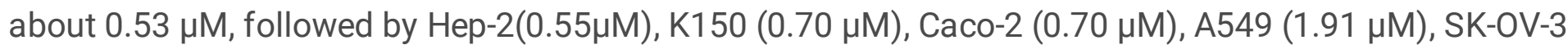
$(1.61 \mu \mathrm{M})$ and HepG2 (1.28 $\mu \mathrm{M}))$ (Fig. 1B).

\section{The selectivity of BR was assessed using normal cell lines}

After incubated with designed doses for $24 \mathrm{~h}, 48 \mathrm{~h}$ and $72 \mathrm{~h}$, the cytotoxicity of BR was detected in the human laryngeal cancer cell line Hep-2 and the normal human bronchial epithelial cell line BEAS-2B. The results demonstrated that $\mathrm{BR}$ markedly inhibited the proliferation of the Hep-2 cells in a time and concentration-dependent manner (Fig. 1C). The calculated IC50 values at 24,48 and $72 \mathrm{~h}$ were $(0.53 \pm$ $0.13,0.44 \pm 0.08$ and $0.37 \pm 0.10 \mu \mathrm{M})$, respectively. Nevertheless, no significant difference of cell viability was observed in a normal bronchial cell line BEAS-2B after treated with BR for 24,48 and $72 \mathrm{~h}$ (Fig. 1D).

\section{BR induces cell apoptosis in Hep-2 cells}

To investigate whether BR-mediated cytotoxic effect on Hep-2 cells was related to the induction of apoptosis or necrosis, Hoechst 33258 nuclear staining was performed. As shown in Fig. 2A\&B, compared with the control cells, the cells treated with BR exhibited a significantly increase in the levels of apoptotic chromatin condensation, nuclear fragmentation and shrinkage as well as the number of dead cells. Data from Flow cytometry analysis (FCM) also demonstrated that BR treatment generated more apoptotic cells $(2.65 \pm 0.48 \%, 11.58 \pm 2.56 \%, 25.95 \pm 1.89 \%$ at $0.2,0.4$ and $0.6 \mu \mathrm{M}$ of $\mathrm{BR}$, respectively) than that in the control group (1.52 $\pm 1.10 \%$ ) (Fig. $2 \mathrm{C}$ and $2 \mathrm{D}$ ).

\section{BR elicits S cell cycle arrest in Hep-2 cells}

In order to further determine whether the anti-proliferation activity of BR in Hep-2 cells is related to cell cycle arrest, Hep-2 cells were respectively exposed to different concentrations of $B R(0,0.2,0.4,0.6 \mu \mathrm{M})$ for $48 \mathrm{~h}$, and FCM was employed to analyze the cell cycle distribution. As shown in Fig. 2E and 2F, compared with the control cells, BR treatment resulted in a marked accumulation of S-phase cells, and reduced the percentage of cells in G1 phase. Quantification of cell cycle distribution suggested that BR treatment caused the cell cycle to stagnate in $\mathrm{S}$ phase and induced cell apoptosis in Hep-2 cells in a dose -related fashion.

\section{BR suppresses the metastasis of Hep-2 cells}

Then, we evaluated the effects of BR on cell migration and invasion using transwell assay. As indicated in Fig. 3, migration and invasion of Hep-2 cells were significantly inhibited after BR exposure in a concentration-dependent manner, meanwhile the untreated cells were found to actively invade through the matrigel.

\section{BR reverses the EMT process of Hep-2 cells}


EMT is an important physiological process in the migration and invasion of malignant tumor cells [21]. Following treatment with $0.2,0.4$ and $0.6 \mu \mathrm{M} \mathrm{BR}$ for $48 \mathrm{~h}$, IHC analysis was performed to evaluate the EMT-associated proteins. Compared with the control group, BR treatment groups decreased the expression of Hep-2 cells mesenchymal markers N-cadherin, Vimentin, snail and upregulated the expression of the epithelial marker E-cadherin (Fig. 5), the regulation of EMT markers appeared to be dependent on the dose of BR applied. Additionally, in parallel with the IHC experimental results, the above results were also verified by qRT-PCR analysis (Fig. 4A, 4B, 4C and 4D). As expected, the mRNA expression of these EMT-related markers was regulated by $B R$ in a dose-dependent manner. These observations suggested that BR diminished the EMT process in Hep-2 cells.

\section{BR abrogates the JAK2/STAT3 signaling pathways in Hep-2 cells}

To further elucidate the potential mechanisms of the anti- tumor activity exerted against Hep-2 cells by BR, the expression levels of JAK2/STAT3 and their phosphorylated forms after exposure to BR were investigated. As shown in Fig. 6, compared with the control group, BR dose-dependently suppressed the protein expression levels of JAK2/STAT3 as well as phosphorylation levels in Hep-2 cells. In addition, qRT-PCR analyses were also carried out to clarify whether the reduction of protein levels of STAT3 and JAK2 were due to the inhibition of gene expressions. As exhibited in Fig. 4E and 4F, the mRNA levels of STAT3 and JAK2 were down regulated by BR in a dose-dependent manner. All above results indicated that BR not only inhibited the phosphorylation of JAK2/STAT3 but also negatively regulated the gene expression of JAK2/STAT3 in Hep-2 cells. In summary, these data suggested that BR could abrogate the activity of JAK/STAT3 signaling pathway in Hep-2 cells.

\section{BR Inhibited Tumor Growth in the Hep-2 Subcutaneous Tumor Xenograft Mouse Model}

Male Balb/c mice with Hep-2 tumor cells were used to evaluate the anti-tumor activity of BR in vivo. The experimental protocol is depicted in Fig. 7A. The anti-tumor activities were assessed by comparing body weight, tumor volume, tumor weight and changes in various organs and tissues. The morphological changes of the tumor were illustrated in Fig. 7G, and the growth of laryngeal cancer was obviously inhibited by BR group and Cis group. After 20 days administration, BR at doses of 1.0 and $2.0 \mathrm{mg} / \mathrm{kg}$ and Cis at dose of $5 \mathrm{mg} / \mathrm{kg}$ significantly decreased in the tumor weights by $42.15 \pm 8.29 \%, 57.55 \pm 4.91 \%$ and $53.09 \pm 4.85 \%$, respectively (Fig. 7D). The tumor volumes were increased slower in the 1.0 and $2.0 \mathrm{mg} / \mathrm{kg}$ $\mathrm{BR}$ and $\mathrm{Cis}$ groups than in the control group $(\mathrm{P}<0.05)$ (Fig. 7B). It was worth noting that mean body weight was not significantly different in $B R$ and control group $(P>0.05)$. Whereas the weight of Cis group significantly lower than the control group $(P<0.05)$, suggesting that compared to Cis group, BR exhibited fewer side effects (Fig. 7C). By calculating spleen and thymus index, it was found that compared with the positive drug (Fig. 7E\&F), BR group could maintain the spleen and thymus quality of mice at normal level, 
indicating that the side effects of BR were not obvious, and its tumor inhibition mechanism might be different from that of cisplatin.

To further explore the toxicity of the drug in vivo. The heart, liver, spleen, lung, kidney and tumor tissues were made into sections and H\&E stained to evaluate the toxicity of BR on different tissues. The results were shown in Fig. 7H. The kidneys, lungs, spleen, liver and heart in the normal group (normally fed mice without tumor inoculation), the control group and the BR group showed no damage. However, the Cis group caused a small amount of hepatocyte necrosis at the edge of the liver tissue of the mouse, and the nucleus was deeply stained and fragmented, and the cytoplasm was increased in eosinophilia (red arrow), which caused liver damage. A large amount of renal tubular epithelial edema at the junction of the cortex and medulla of the kidney tissue, swelling of the cells and faintly stained cytoplasm (black arrow) cause kidney damage.

At the same time, we observed that the tumor cells in the control group were tightly arranged and disordered, with larger nuclei, rich cytoplasm, darker staining and less stroma. A large amount of inflammatory cell infiltration can be seen at the edge of tumor tissue in BR group. And we can observe that nuclei were abnormal, high nucleo-plasm ratio, nucleolus was not obvious and mitotic phase was rare. Furthermore, it's still observable that moderate cell necrosis, nucleus pyknosis, fragmentation or lysis eosinophilia is enhanced, forming a typical phenomenon of apoptotic bodies. Taken together, these results strongly suggested that BR inhibited the growth of Laryngeal cancer in vivo.

\section{Discussion}

LSCC has the second highest incidence among Head and neck squamous cell carcinoma (HNSCC) and is especially prevalent in the northern areas of China, including Shanxi Province [22]. Due to adverse effects and poor prognosis of the existing treatments, it is extremely urgent to explore alternative anticancer drugs with appreciable efficacy and minimized toxic effects from medicinal plants. BR is the primary active component of Brucea javanica, and has been reported to possess effective extensive bioactivities including anti-inflammatory, antitumor, antimalarial, antiviral and insecticide activities [20]. In spite of various works have evaluated the vital roles of BR in tumors, reports on the role of BR in LSCC are rare. Our work also proved that BR exerted potent growth inhibitory activities against a broad spectrum of human cancer cell lines. Among these cells, Hep-2 cells were the most sensitive to BR. Hence, in the current study, we firstly use a human laryngeal carcinoma Hep-2 cell line to investigate the effect of BR on LSCC and explored its mechanism of action.

The proliferative capacity of tumor cells is considered pivotal for the growth and development of tumors [23]. In the current research, we firstly exposed Hep-2 cell line to increasing concentrations of BR at different time periods and the IC50 values were evaluated using a CCK-8 method. The results demonstrated BR significantly inhibited the proliferation of Hep-2 in a dose- and time- dependent manner. Meanwhile, mild cytotoxic effect was observed on normal human bronchial epithelial cell line (BEAS-2B), 
indicating that BR might be a highly selective killing agent toward laryngeal cancer cells in a certain concentration range.

Apoptosis is a programmed cell death process which includes series of biochemical events leading to several vital featured morphological alternations, for example, cell shrinkage, chromatin condensation, and nucleus DNA fragmentation [24]. The induction of apoptosis is presumed to factor prominently in most anti-tumor therapy mechanisms [25]. The results displayed indicated that the cell morphology changed obviously: the cell edge was abnormal, the adherence ability declined, the chromatin condensed, the fluorescence became dense, and bright blue spots (apoptotic bodies) could be seen. In parallel with the morphological results, Annexin V-FITC/PI double staining also confirmed that BR could induce Hep-2 cells apoptosis.

Cell cycle is the essential mechanism during reproduction of all living things [26]. Loss of cell cycle control is one of the typical characteristics of tumorigenesis [27]. In this study, we have found that BR induction markedly increased proportion of $S$ phase in Hep-2 cells. These results suggested that BR might result in cell cycle arrest and result in DNA fragmentation.

Tumor metastasis is a complicated course which acts as a considerable malignant behavior in the process of tumor development and progression. Migration and invasion are two different cellular forms in tumor metastasis [14]. In our study, different concentrations of BR were used for transwell assays, which indicated that BR significantly inhibited Hep-2 cells migration and invasion in a dose-dependent manner, suggesting that BR exerts a potent anti-migratory effect on Hep-2 cells. EMT, one of the distinctive characteristics of tumor metastasis, is a biological process featured by cellular and molecular changes [28]. When EMT occurs, the expression of an epithelial marker, such as E-cadherin, is reduced, whereas that of mesenchymal markers, such as $\mathrm{N}$-cadherin, Vimentin and Snail, are increased [29]. Hence, a reversal of the EMT process is regarded as a latent strategy to ameliorate the migration and invasiveness of malignant tumors. Immunohistochemistry analysis and qRT-PCR results revealed that BR inhibited the activation of EMT via the downregulation of mesenchymal biomarkers $\mathrm{N}$-cadherin, Vimentin, Snail and upregulation of the epithelial biomarker E-cadherin, consequently suppressed migration and invasion in cancer cells. These findings imply that the BR may possess the ability to control metastasis of laryngeal cancer.

STAT3 is a potential transcription factor, it acted as a pivotal role in the transcriptional activation of cell apoptosis and cycle progression [30]. STAT3 can be activated by the activation of JAK2, a non-receptor tyrosine kinase. Upon activation, STAT3 undergoes phosphorylation-induced homodimerization and translocates into the nucleus where it regulates its target gene [31, 32]. The JAK2/STAT3 signaling pathway is constitutively activated in varieties of malignant tumors and plays a critical role in multiple biological processes [33]. Thus, inhibition of this signaling pathway is considered as a promising therapeutic target for cancer therapy. Moreover, a series of studies have proved that the activation of JAK2/STAT3 pathway devotes to progression of EMT in multiple cancer cells [34]. Previous reports indicated that the phosphorylation of STAT3 is overactive in Hep-2 and TU212 cells and implicated in cell 
proliferation, invasion and migration [35]. In our current study, the western blotting results revealed that BR could inhibit the JAK2/STAT3 signaling pathway by reducing the protein expression and phosphorylation levels in Hep-2 cells.

In addition, the anti-tumor effect of BR was further verified by in vivo experiment. At a dose of $2 \mathrm{mg} / \mathrm{kg}$, BR significantly inhibited tumor growth in a xenograft model of laryngeal cancer, the tumor volume was reduced by about $30 \%$, which was comparable to the Cis group. Moreover, the Cis group caused a significant weight loss (16\%) in mice, while there was no significant difference in weight between the BR group and the control group. H\&E staining demonstrated that cisplatin caused liver and kidney damage, and BR has no effect on vital organs. Therefore, our in vivo experimental results provide additional support for BR as an effective and non-toxic treatment for LC.

In summary, our study is the first one to define the mechanism of activity of BR in human laryngeal carcinoma. These novel findings demonstrated that BR was found to suppress the tumor growth both in vivo and in vitro, at least partially, through its abrogation of JAK2/STAT3 signaling pathway mediatedEMT process. Our pioneering endeavor also manifested that BR exerted similar anti-laryngeal cancer effect as the current first-line agent cisplatin with much smaller dosage and advantageous safety profile. All these findings provide solid evidence that BR may be an attractive candidate drug for future laryngocarcinoma therapeutics. Moreover, all these effects need to be investigated using clinical samples and further studies are underway.

\section{Abbreviations}

BR: brusatol; EMT: epithelial-mesenchymal transition; LC: laryngeal cancer; LSCC: laryngeal squamous cell carcinoma; FBS: fetal bovine serum; TBST: tris-buffered saline with Tween; FCM: flow cytometry; JAK2: janus kinase 2; STAT3: signal transducer and activator of transcription 3; Cis: cisplatin.

\section{Declarations}

\section{Ethics approval and consent to participate}

Not applicable.

\section{Consent for publication}

Not applicable.

\section{Availability of data and materials}

The data that support the findings of this study are available from the corresponding author upon reasonable request. 


\section{Competing interests}

The authors have declared that no competing interest exists.

\section{Funding}

This work was sponsored by the National Natural Science Foundation of China (81904031), Plan of Shanxi Province Science and Technology Research (201901D211325), Shanxi Higher Education Innovation Project (2019L0448), Science Research Start-up Fund for Doctor of Shanxi province (SD1801), Science Research Start-up Fund for Doctor of Shanxi Medical University (XD1802) and the National Key R\&D Program of China (2019YFC1710800).

\section{Authors' contributions}

Jiangtao Zhou and Jing Hou conceived and designed the experiment. Jun Wang and Jiajing Wang acquired and analyzed the data. Jianping Gao and Yun'e Bai confirmed the authenticity of all the raw data. Jiangtao Zhou prepared the draft of the manuscript, including the figures. All authors read and approved the final manuscript.

\section{Acknowledgements}

Not applicable.

\section{References}

1. Gao C, Hu S. miR-506 is a YAP1-dependent tumor suppressor in laryngeal squamous cell carcinoma. Cancer Biol Ther. 2019; 20: 826-36. https://doi.org/10.1080/15384047.201 8.1564569.

2. Wan B, Zang Y, Lin W. Overexpression of Beclin1 inhibits proliferation and promotes apoptosis of human laryngeal squamous carcinoma cell Hep-2. Oncotargets Therapy. 2018;11:3827-33. https://doi.org/10.2147/OTT.S148869.

3. Lin SX, Jiang H, Xiang GZ, Zhang WR, Weng YH, Qiu FD, et al. Up-regulation of long non-coding RNA SNHG1 contributes to proliferation and metastasis in laryngeal squamous cell carcinoma. Eur Rev Med Pharmacol Sci. 2018: 1333-41. https://doi.org/10.26355/eurrev _201803_14475.

4. Kuper H, Boffetta P, Adami HO. Tobacco use and cancer causation: association by tumour type. J Intern Med. 2002; 252: 206 - 24. https://doi.org/10.1046/j.1365-2796.2002.01022.x.

5. Fang R, Huang Y, Xie J, Zhang J, Ji X. Downregulation of miR-29c-3p is associated with a poor prognosis in patients with laryngeal squamous cell carcinoma. Diagnostic pathology. 2019;14:109. https://doi.org/10.1186/s13000-019-0893-2. 
6. Wang L, Sun J, Gao P, Su K, Lou W. Wnt1-inducible signaling protein 1 regulates laryngeal squamous cell carcinoma glycolysis and chemoresistance via the YAP1/TEAD1/GLUT1 pathway: WANG et al. J Cell Physiol. 2019; 234: 15941-50. https://doi.org/10.1002/jc p.28253.

7. Wan B, Zang Y, Wang L. Overexpression of Beclin1 inhibits proliferation and promotes apoptosis of human laryngeal squamous carcinoma cell Hep-2. Oncotargets Therapy. 2018; 11: 3827-33. https://doi.org/ 10.2147/OTT.S148869.

8. Sun X, Wang Q, Wang Y, Du L, Xu C, Liu Q. Brusatol Enhances the Radiosensitivity of A549 Cells by Promoting ROS Production and Enhancing DNA Damage. Int J Mol Sci. 2016; 17 : 997. https://doi.org/ 10.3390/ijms17070997.

9. Zhan Y, Tan T, Qian K, Yang S, Feng Y, Wen Q. Quassinoids from seeds of Brucea Javanica and their anticomplement activities. Nat Prod Res. 2020; 34: 1186-91. https://doi.org/ 10.1080/14786419.2018.1550764.

10. Cai SJ, Liu Y, Han S, Yang C. Brusatol, an NRF2 inhibitor for future cancer therapeutic. Cell bioscience. 2019; 9: 45. https://doi.org/ 10.1186/s13578-019-0309-8.

11. Oh ET, Kim CW, Kim HG, Lee JS, Park HJ. Brusatol-Mediated Inhibition of c-Myc Increases HIF-1a Degradation and Causes Cell Death in Colorectal Cancer under Hypoxia. Theranostics. 2017;7:341531. https://doi.org/10.7150/thno.20861.

12. Chen HM, Lai ZQ, Liao HJ, Xie JH, Xian YF, Chen YL, et al. Synergistic antitumor effect of brusatol combined with cisplatin on colorectal cancer cells. Int J Mol Med. 2018;41:1447-54. https://doi.org/10.3892/ijmm.2018.3372.

13. Wang $\mathrm{Y}$, Li H, Huang H, Liu S, Mao X, Wang S, et al. Cardioprotection from emulsified isoflurane postconditioning is lost in rats with streptozotocin-induced diabetes due to the impairment of Brg1/Nrf2/STAT3 signalling. Clinical science (London, England: 1979). 2016; 130: 801 - 12. https://doi.org/10.1042/CS20150617.

14. Chen Y, Wu H, Wang X, Wang C, Gan L, Zhu J, et al. Huaier Granule extract inhibit the proliferation and metastasis of lung cancer cells through down-regulation of MTDH, JAK2/STAT3 and MAPK signaling pathways. Biomedicine pharmacotherapy 2018; 101: 311-21. https://doi. org/10.1016/j.biopha.2018.02.028.

15. Guo X, Yan Z, Zhang G, Wang X, Pan Y, Huang M. STIP1 Regulates Proliferation and Migration of Lung Adenocarcinoma Through JAK2/STAT3 Signaling Pathway. Cancer management research. 2019;11:10061-72. https://doi.org/10.2147/CMAR.S233758.

16. Xia L, Zhang B, Yan Q, Ruan S. Effects of saponins of patrinia villosa against invasion and metastasis in colorectal cancer cell through NF-kappaB signaling pathway and EMT. Biochemical and biophysical research communications. 2018; 503: 2152-9. https://doi.org/10.1016/j.bbrc. 2018.08.005.

17. Ye R, Dai N, He Q, Guo P, Xiang Y, Zhang Q, et al. Comprehensive anti-tumor effect of Brusatol through inhibition of cell viability and promotion of apoptosis caused by autophagy via the PI3K/Akt/mTOR 
pathway in hepatocellular carcinoma. Biomedecine pharmacotherapie. 2018;105:962-73. https://doi.org/10.1016/j.biopha.2018.06.065.

18. Lu Z, Lai ZQ, Leung AWN, Leung PS, Li ZS, Lin ZX. Exploring brusatol as a new anti-pancreatic cancer adjuvant: biological evaluation and mechanistic studies. Oncotarget. 2017;8:84974-85. https://doi.org/10.18632/oncotarget.17761.

19. Zhou J, Tan L, Xie J, Lai Z, Huang Y, Qu C, et al. Characterization of brusatol self-microemulsifying drug delivery system and its therapeutic effect against dextran sodium sulfate-induced ulcerative colitis in mice. Drug Deliv. 2017; 24: 1667-79. https://doi.org/ 10.1080/10717544.2017.1384521.

20. Tongtong 20 JiangtaoZ, Yaoxing W, Yanfeng D, Chang H, Jiansheng Q. G, et al. Brusatol ameliorates 2, 4, 6-trinitrobenzenesulfonic acid-induced experimental colitis in rats: Involvement of NF-kB pathway and NLRP3 inflammasome. Int Immunopharmacol. 2018;64:264-74. https://doi.org/10.1016/j.intimp.2018.09.008.

21. Luo C, Wang Y, Wei C, Chen Y, Ji Z. The anti-migration and anti-invasion effects of Bruceine $D$ in human triple-negative breast cancer MDA-MB-231 cells. Experimental therapeutic medicine. 2020;19:273-9. https://doi.org/10.3892/etm.2019.8187.

22. Ji W, Guan C, Pan Z. Analysis of curative effects on laryngeal carcinoma patients in the northeast region of China. Acta oto-laryngologica. 2008; 128: 574-7. https://doi.org/ 10.1080/00016480701596104.

23. Cao W, Li XQ, Wang X, Fan HT, Zhang XN, Hou Y, et al. A novel polysaccharide, isolated from Angelica sinensis (Oliv.) Diels induces the apoptosis of cervical cancer HeLa cells through an intrinsic apoptotic pathway. Phytomedicine: international journal of phytotherapy phytopharmacology. 2010;17:598-605. https://doi.org/10.1016/j.phymed.2009.12.014.

24. Lai ZQ, Ip SP, Liao HJ, Lu Z, Xie JH, Su ZR, et al. Brucein D, a Naturally Occurring Tetracyclic Triterpene Quassinoid, Induces Apoptosis in Pancreatic Cancer through ROS-Associated PI3K/Akt Signaling Pathway. Front Pharmacol. 2017; 8: 936. https://doi.org/ 10.3389/fphar.2017.00936.

25. Han J, Lv W, Sheng H, Wang Y, Cao L, Huang S, et al. Ecliptasaponin A induces apoptosis through the activation of ASK1/JNK pathway and autophagy in human lung cancer cells. Annals of translational medicine. 2019;7:539. https://doi.org/10.21037/atm.2019.10.07.

26. Wen SY, Chen YY, Deng CM, Zhang CQ, Jiang MM. Nerigoside suppresses colorectal cancer cell growth and metastatic potential through inhibition of ERK/GSK3beta/beta-catenin signaling pathway. Phytomedicine: international journal of phytotherapy phytopharmacology. 2019;57:35263. https://doi.org/10.1016/j.phymed.2018.12.033.

27. Yu H, Yin S, Zhou S, Shao Y, Sun J, Pang X, et al. Magnolin promotes autophagy and cell cycle arrest via blocking LIF/Stat3/Mcl-1 axis in human colorectal cancers. Cell death disease. 2018;9:702. https://doi.org/10.1038/s41419-018-0660-4.

28. Li W, Zhang X, Wu F, Zhou Y, Bao Z, Li H, et al. Gastric cancer-derived mesenchymal stromal cells trigger M2 macrophage polarization that promotes metastasis and EMT in gastric cancer. Cell death disease. 2019;10:918. https://doi.org/10.1038/s41419-019-2131-y. 
29. Gonzalez DM, Medici D. Signaling mechanisms of the epithelial-mesenchymal transition. Sci Signal. 2014;7:re8. https://doi.org/10.1126/scisignal.2005189.

30. Yu H, Pardoll D, Jove R. STATs in cancer inflammation and immunity: a leading role for STAT3. Nature reviews Cancer. 2009;9:798-809. https://doi.org/10.1038/nrc2734.

31. Heesel CBJJoB. Differential Activation of Acute Phase Response Factor/STAT3 and STAT1 via the Cytoplasmic Domain of the Interleukin 6 Signal Transducer gp130. I. DEFINITION OF A NOVEL PHOSPHOTYROSINE MOTIF MEDIATING STAT1 ACTIVATION. 271: 12991-8. https://doi.org/10.1074/jbc.271.22.12999.

32. Jarnicki A, Putoczki T, Ernst M. Stat3: linking inflammation to epithelial cancer - more than a "gut". feeling? Cell division. 2010;5:14. https://doi.org/10.1186/1747-1028-5-14.

33. Hu H, Wang S, Shi D, Zhong B, Huang X, Shi C, et al. Lycorine exerts antitumor activity against osteosarcoma cells in vitro and in vivo xenograft model through the JAK2/STAT3 pathway. OncoTargets therapy. 2019;12:5377-88. https://doi.org/10.2147/OTT.S202026.

34. Liu K, Tian T, Zheng Y, Zhou L, Dai C, Wang M, et al. Scutellarin inhibits proliferation and invasion of hepatocellular carcinoma cells via down-regulation of JAK2/STAT3 pathway. J Cell Mol Med. 2019;23:3040-4. https://doi.org/10.1111/jcmm.14169.

35. Liu C, Liu H, Wen Y, Huang H, Hao J, Lv Y, et al. Aspernolide A Inhibits the Proliferation of Human Laryngeal Carcinoma Cells through the Mitochondrial Apoptotic and STAT3 Signaling Pathways. Molecules (Basel, Switzerland). 2019; 24. https://doi.org/10.3390/molecules24061074.

\section{Figures}


A

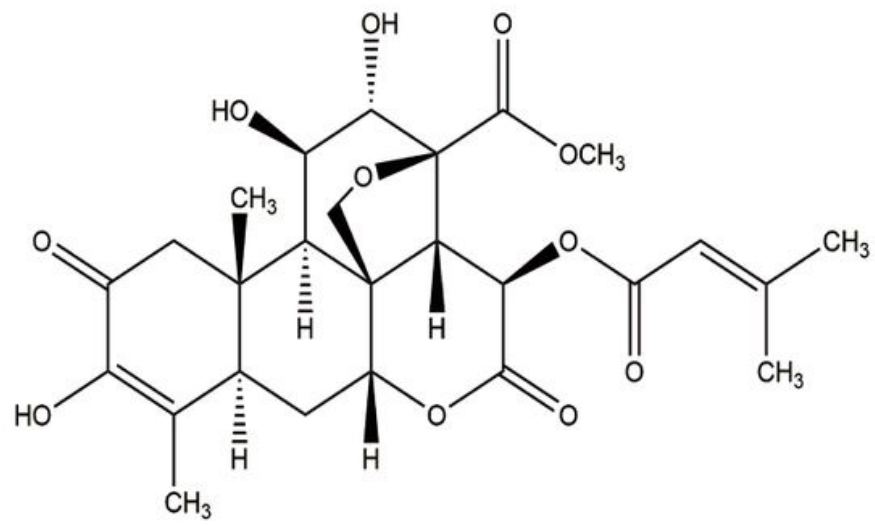

B

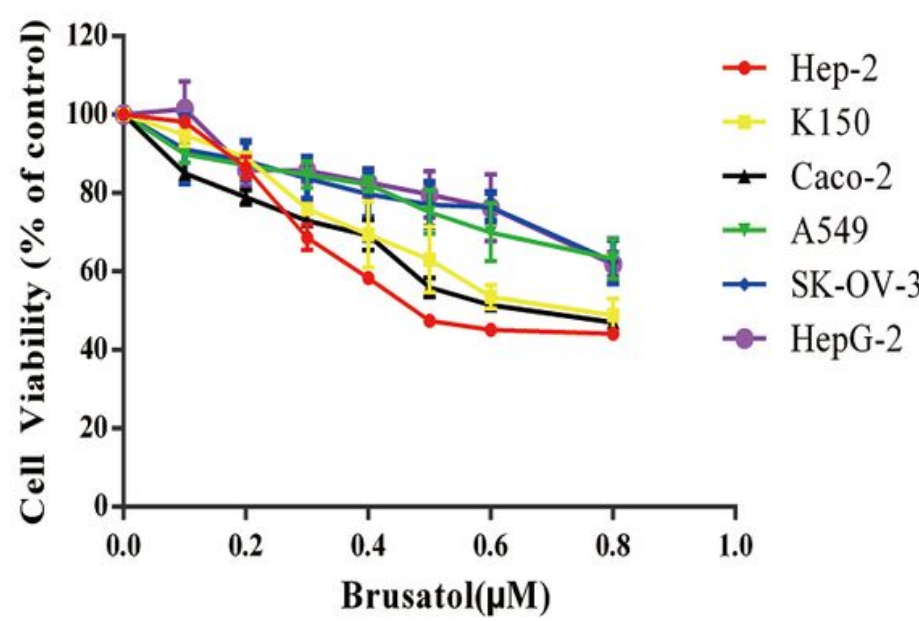

C

Нер-2

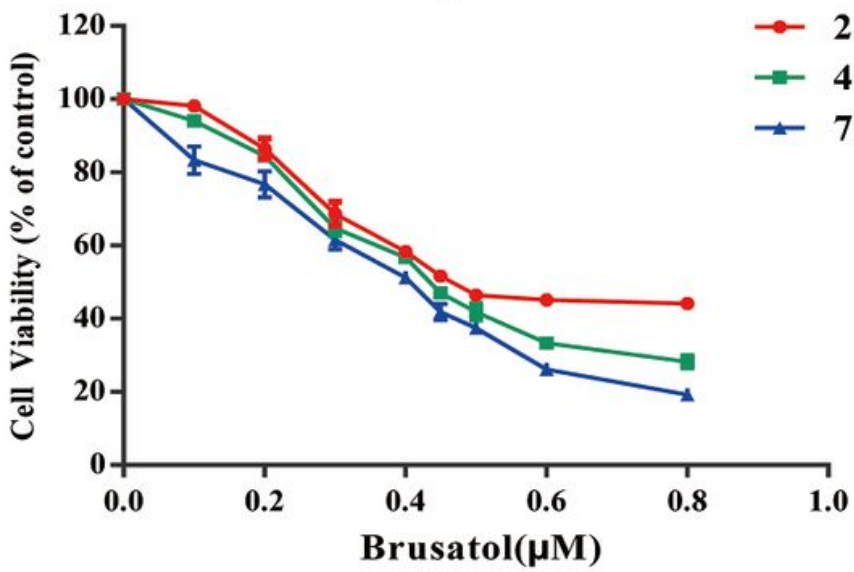

BEAS-2B

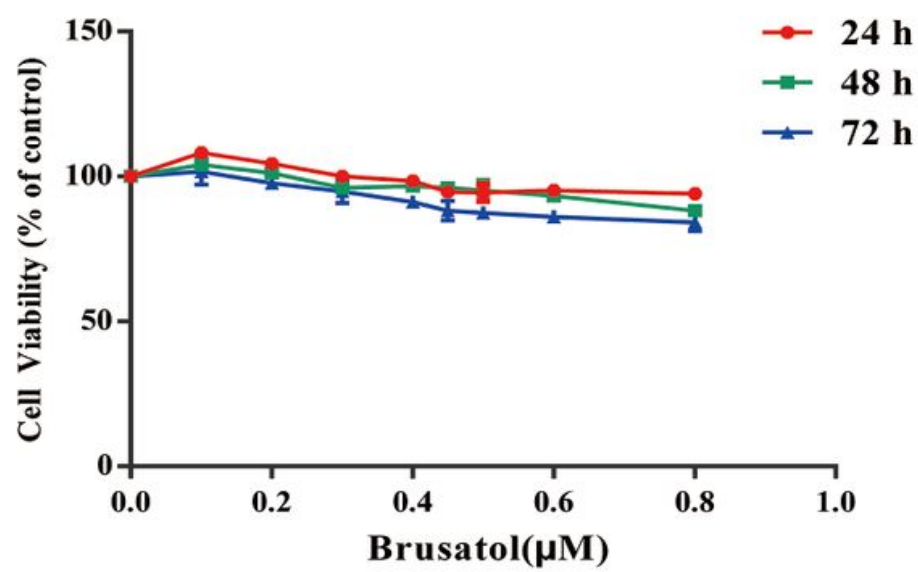

Figure 1

BR inhibits the proliferation in Hep-2 cells. (A) The chemical structure of BR. (B) The proliferation inhibitory effects of BR on six human cancer cells. (C) Hep-2 cells were treated with various concentrations of BR for 24,48 and $72 \mathrm{~h}$. Cell viability was evaluated by performing a CCK-8 assay. (D) BEAS-2B cells were treated with various concentrations of BR for 24,48 and $72 \mathrm{~h}$. Cell viability was evaluated by performing a CCK-8 assay. Each point is the mean \pm SD of three experiments. 


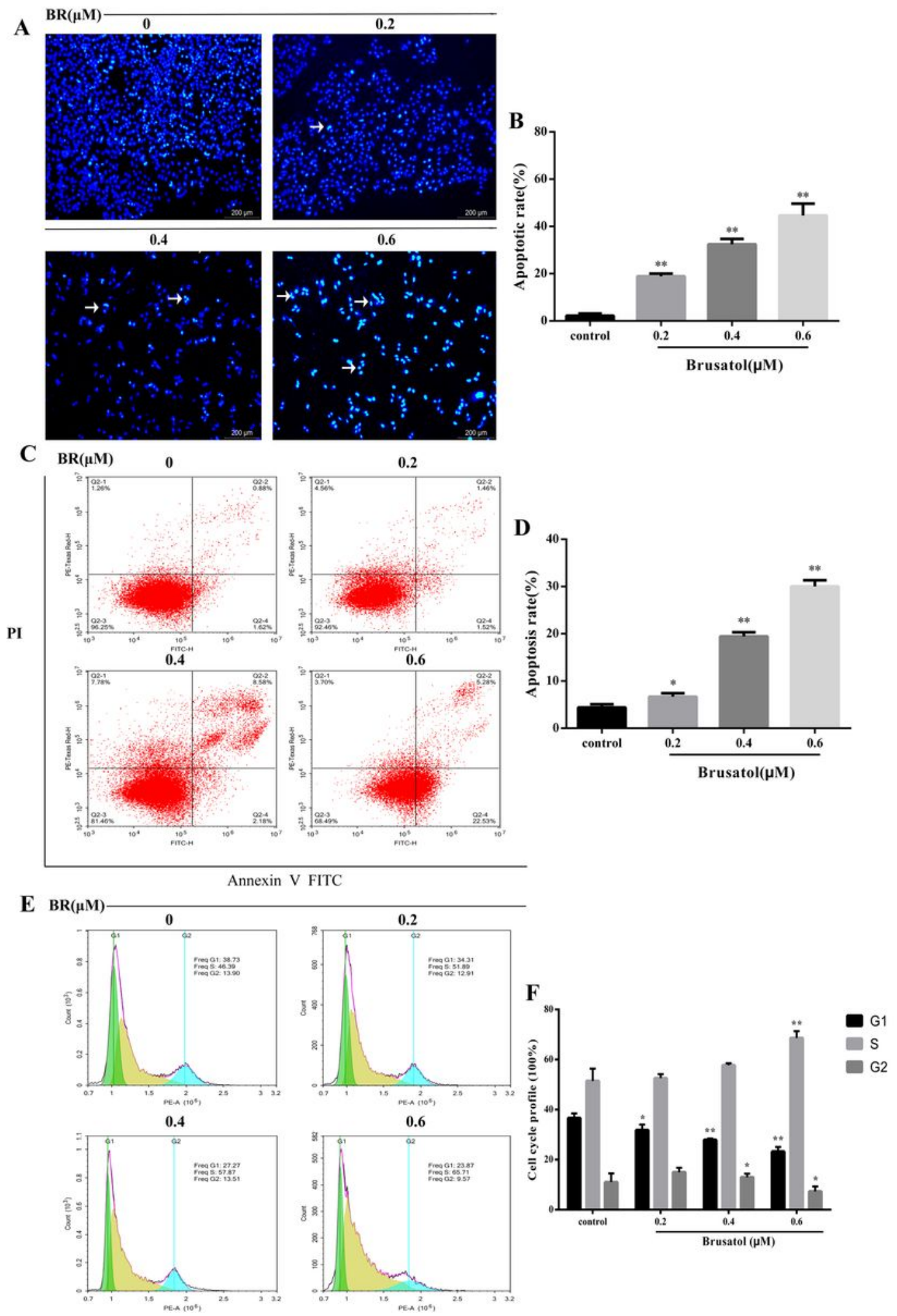

\section{Figure 2}

BR induces cell apoptosis and S-phase arrest in Hep-2 cells. (A) Cell apoptosis observed with Hoechst 33258 staining, scale bar is $200 \mu \mathrm{m}$. Representative fluorescence images of Hoechst 33258 positive cells are shown. Chromatin condensation, nuclear fragmentation and apoptotic bodies are indicated by small arrows. (B) The apoptotic rates of Hoechst 33258 staining were calculated. (C) Cell apoptosis were detected by Annexin V-FITC/PI double staining assay. Bar graphs showed the proportion of early and late 
apoptotic cells. (D) The apoptotic rates of flow cytometry apoptosis assay were calculated. (E, F) The cell cycle phases were evaluated by flow cytometry. Data represents means \pm SD of three separate experiments. ${ }^{*} \mathrm{P}<0.05$ and ${ }^{*} \mathrm{P}<0.01$ vs the control group.
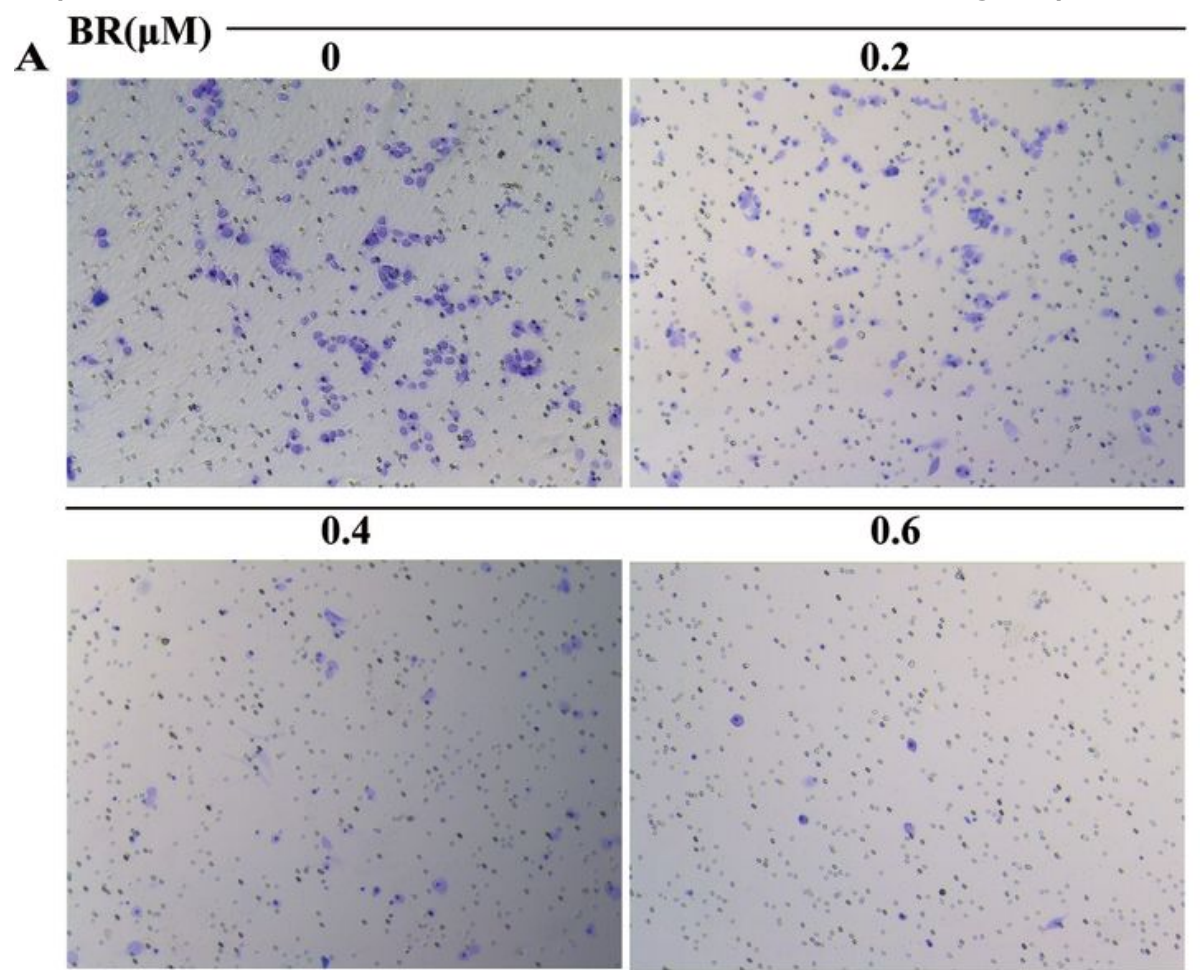

0.6

\section{C}
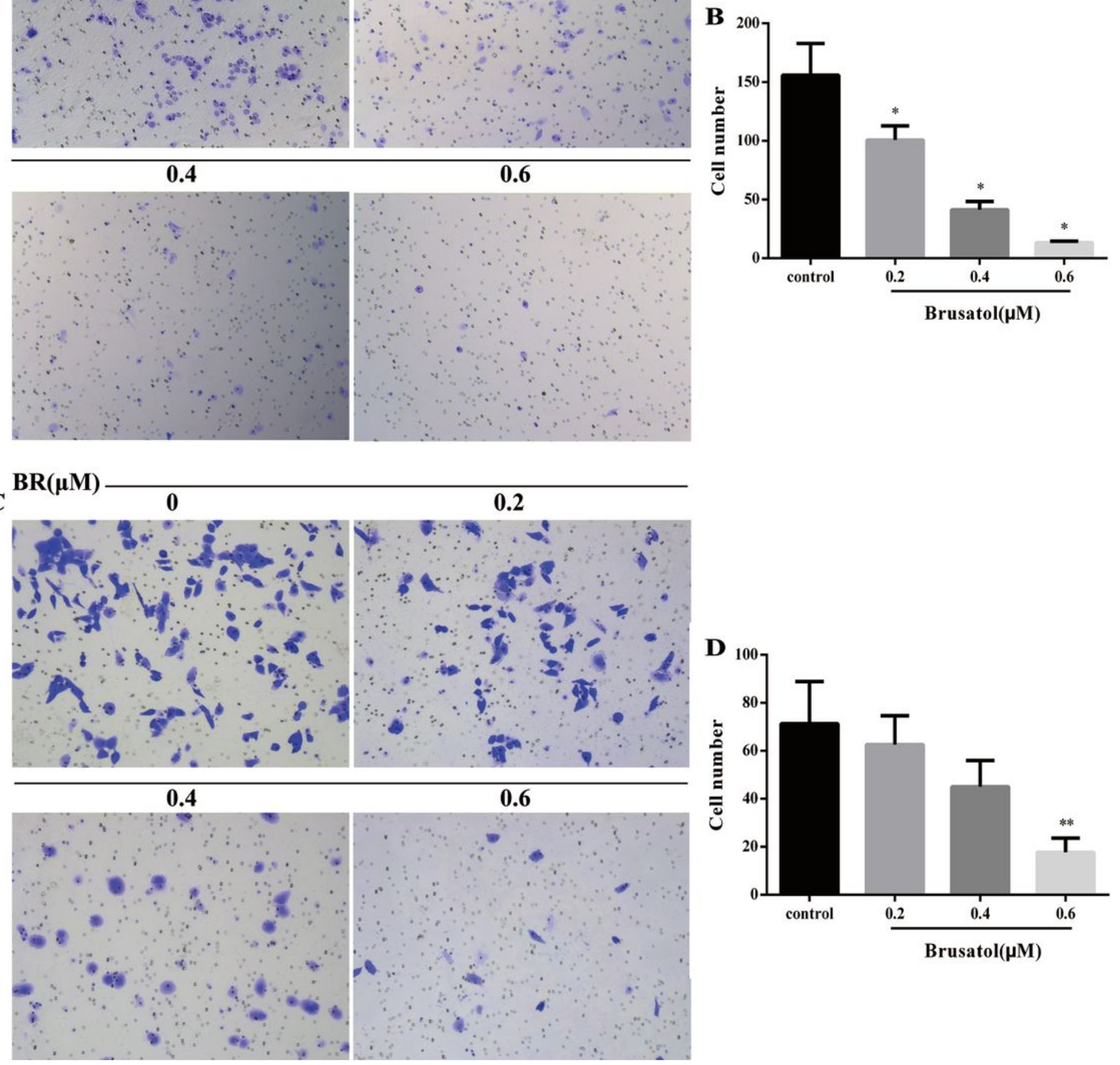

Figure 3

BR suppresses the metastasis of Hep-2 cells. (A, B) Representative images of migration assay and their counting results. (C, D) Representative images of invasion assay and their counting results. Data 
represents means $\pm S D$ of three independent experiments. ${ }^{*} P<0.05$ and $* * P<0.01$ vs the control group.
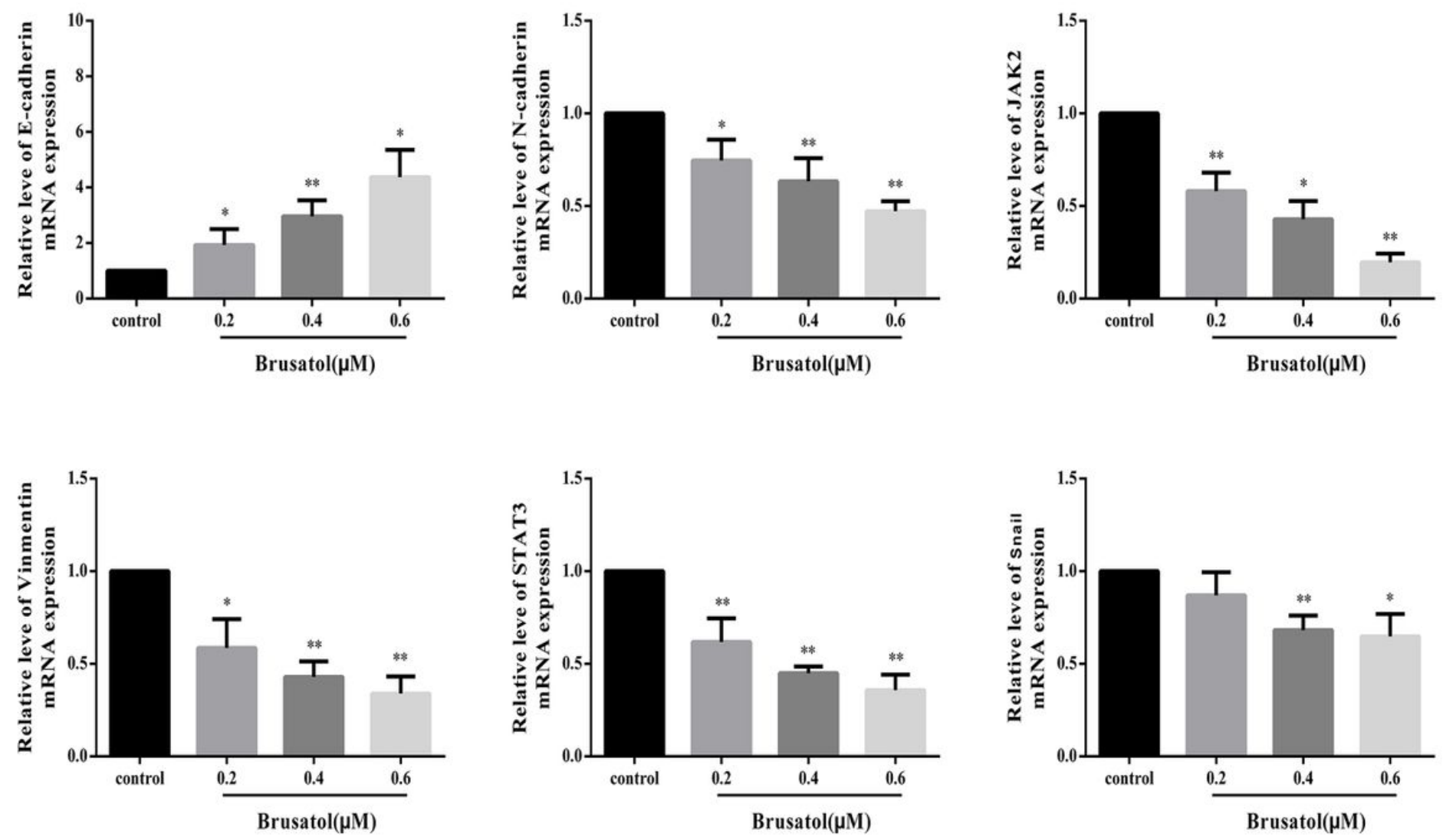

Figure 4

BR regulates the mRNA expression of EMT-related markers and JAK2/ STAT3 in Hep-2 cells. (A) Ecadherin. (B) N-cadherin. (C) Snail. (D) Vimentin. (E) JAK2. (F) STAT3. Data represents means $\pm S D(n=6)$. ${ }^{*} \mathrm{P}<0.05$ and $* * P<0.01$ vs the control group. 


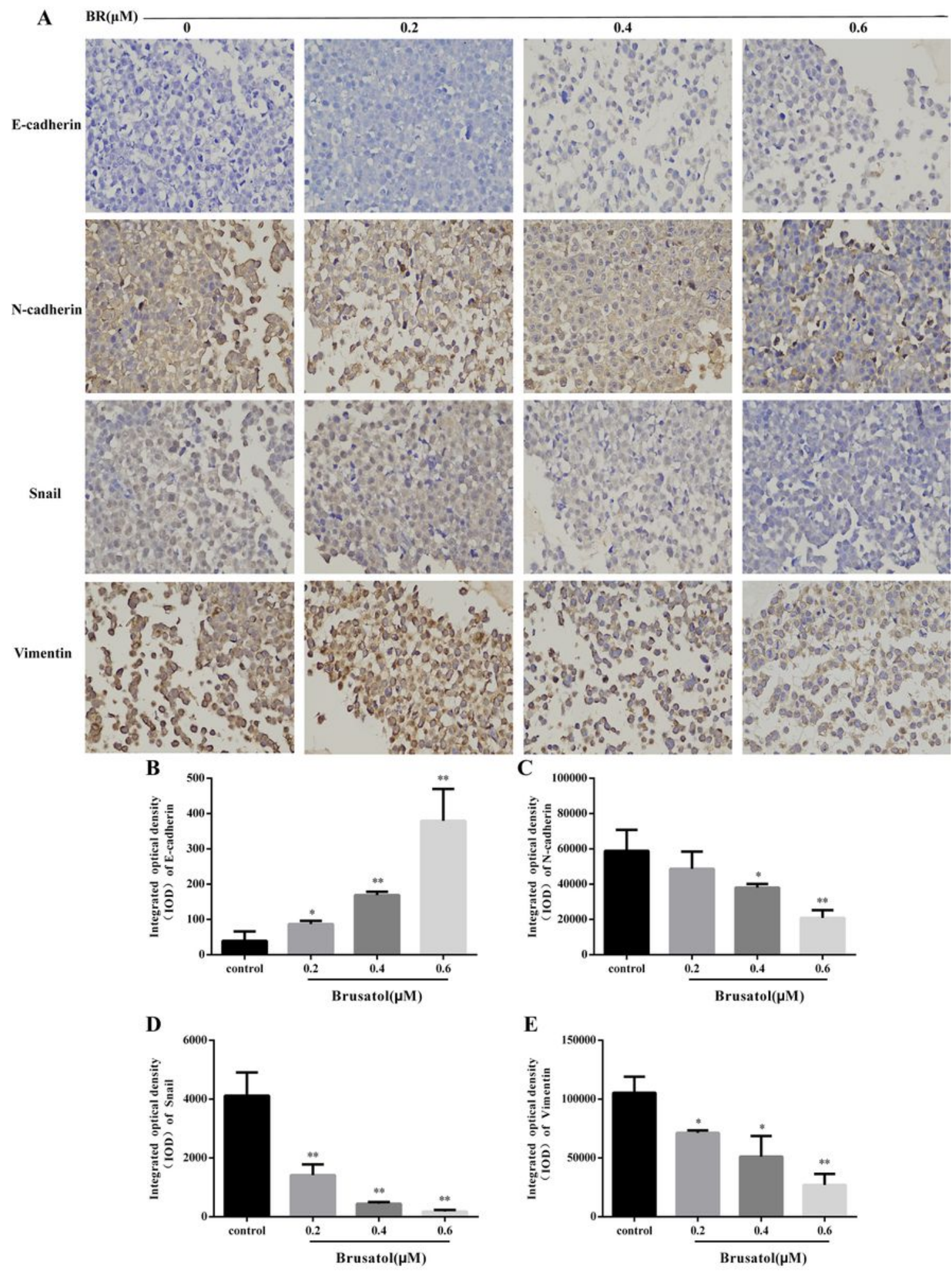

Figure 5

BR reverses the proteins expression of EMT-related markers in Hep-2 cells. (A) Representative immunohistochemical staining (magnification 400x). (B) IOD of E-cadherin. (C) IOD of N-cadherin. (D) IOD of Snail. (E) IOD of Vimentin. Data represents means \pm SD of three independent experiments. ${ }^{*} \mathrm{P}<$ 0.05 and ${ }^{*} \mathrm{P}<0.01$ vs the control group. 


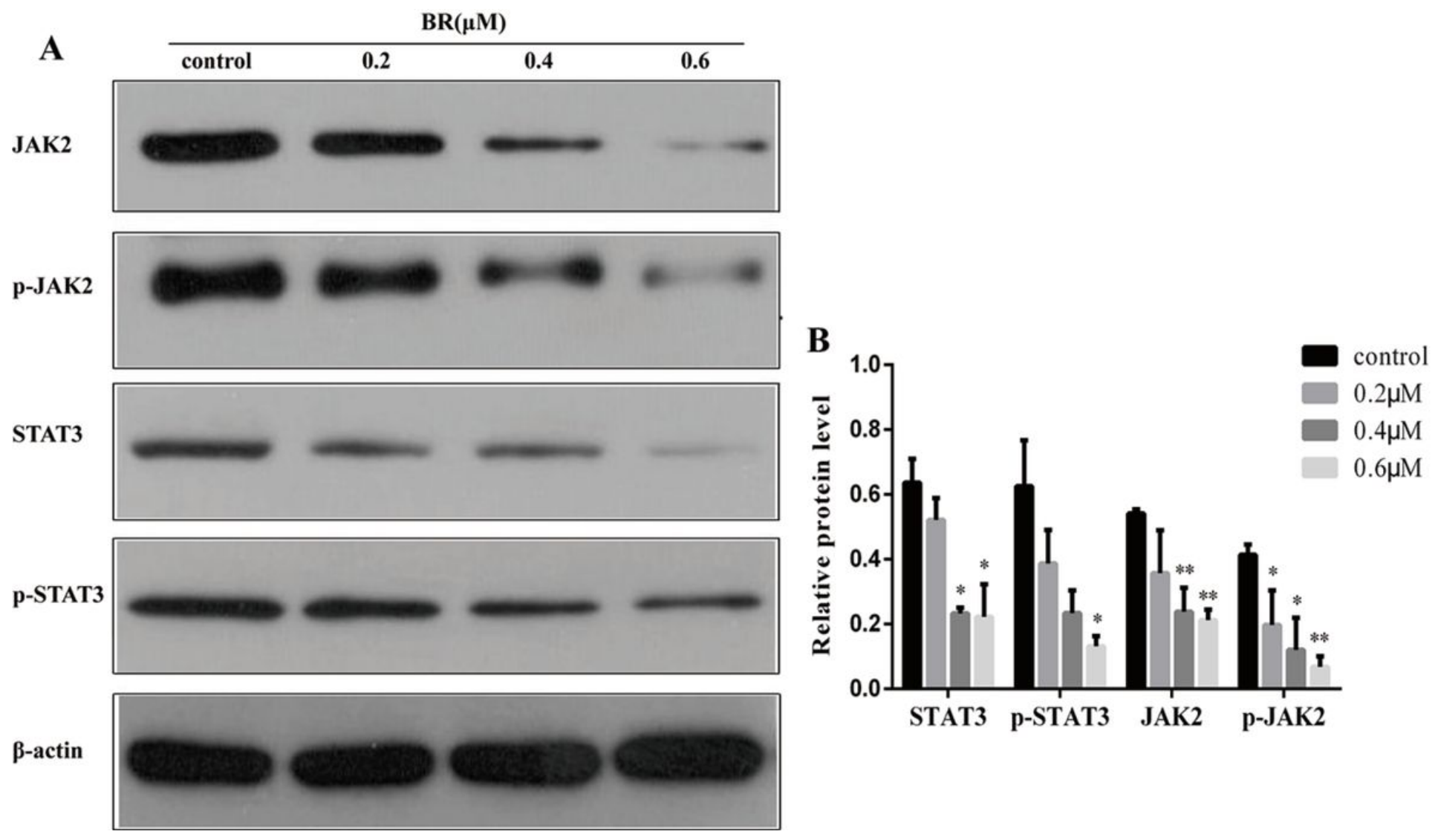

Figure 6

BR inhibits the proteins expression of JAK2/STAT3 and the phosphorylation levels in Hep-2 cells. (A) Representative Western blotting images of JAK2, p-JAK2, STAT3 and p-STAT3 proteins expression in Hep2 cells. (B) Changes in the expression level of STAT3, p-STAT3, JAK2 and p-JAK2. Data represents means $\pm S D$ of three independent experiments. ${ }^{*} P<0.05$ and ${ }^{* * P}<0.01$ vs the control group. 

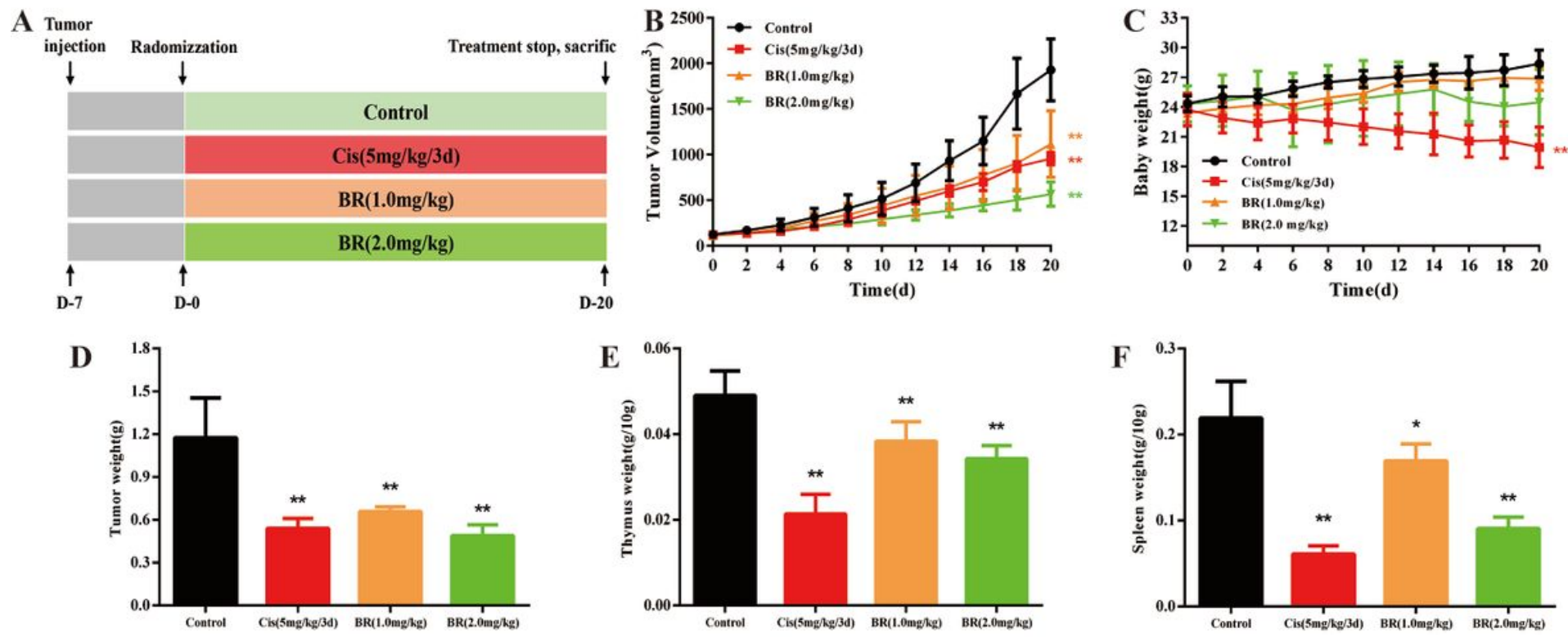

G

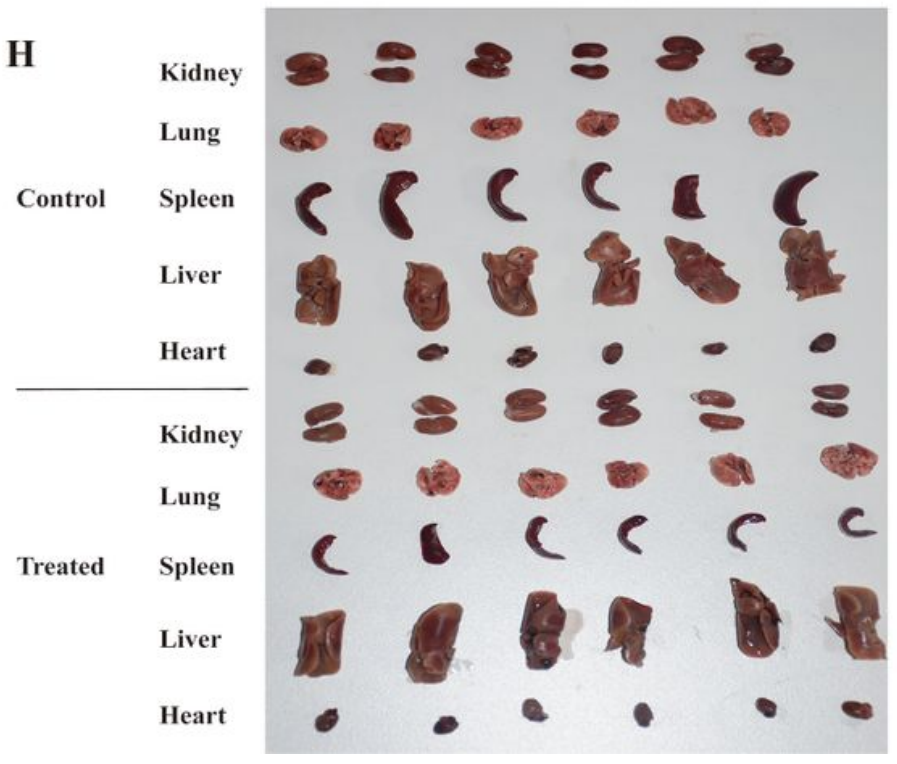

Figure 7

BR significantly inhibited the growth of xenograft tumors of human laryngeal carcinoma in vivo. Hep-2 cells were subcutaneously inoculated into the left armpit of Balb/c mice. When the tumor volume reached about $100 \mathrm{~mm} 3$, intraperitoneal injection of solvent or BR $(1.0$ and $2.0 \mathrm{mg} / \mathrm{kg} / 2 \mathrm{~d})$ or Cis $(3 \mathrm{mg} / \mathrm{kg} / 3 \mathrm{~d})$ was initiated. After 20 days of treatment, all the mice were killed. (A) The experimental protocol. (B)Tumor volumes were measured every 2 days by Vernier caliper. (C) Body weights were measured every 2 days during the test. (D) Comparison of tumor weights at the last measurement. (E, F) Spleen and thymus indexchanges. $(G, H)$ Representative images of xenograft tumors and organs in control, $B R$ and Cis groups. Data represents means $\pm S D$ of six independent experiments. ${ }^{*} \mathrm{P}<0.05$ and ${ }^{*} \mathrm{P}<0.01$ vs the control group. 


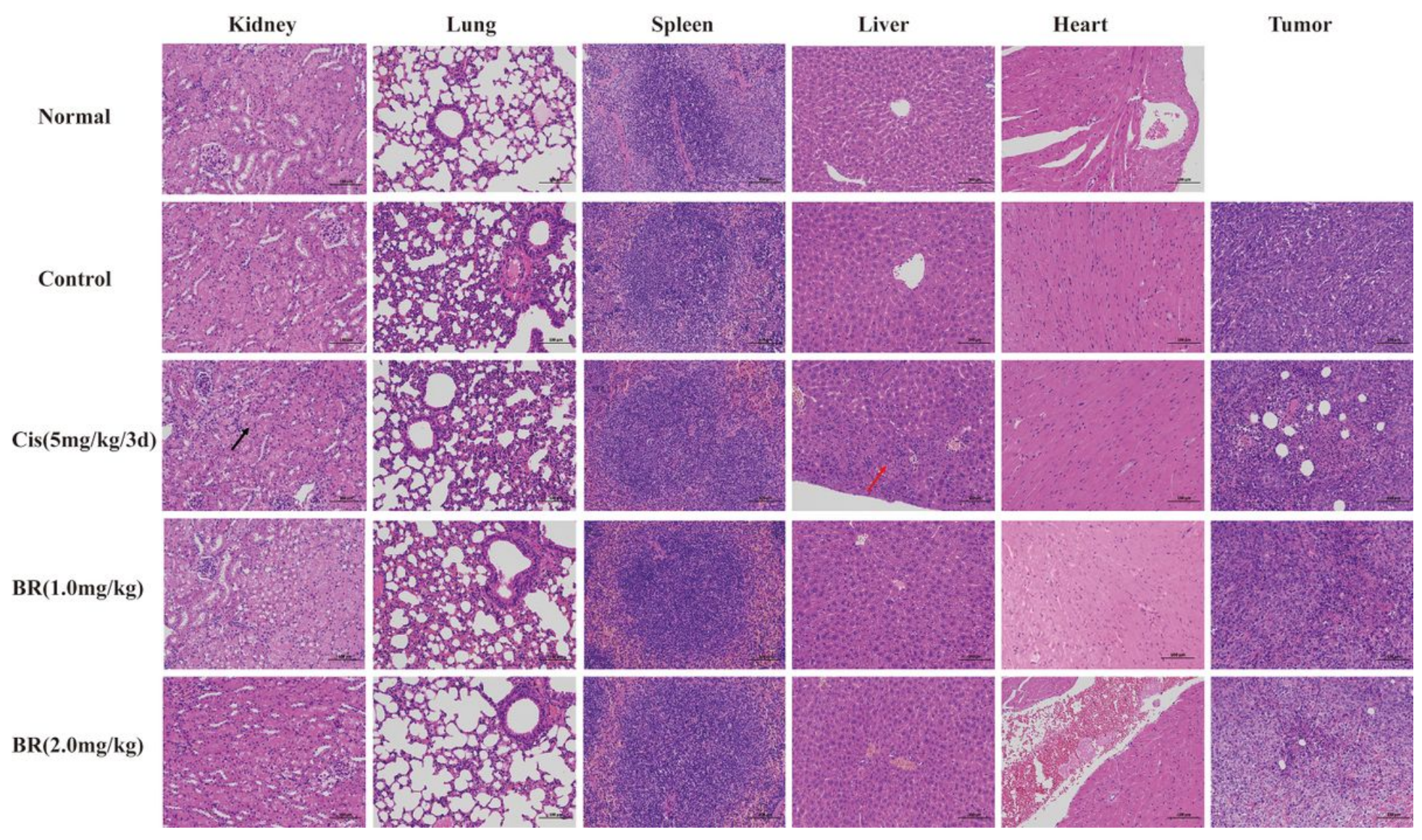

Figure 8

H\&E staining of major organs from each group, including kidney, lung, spleen, liver, heart and tumor. Scale bars $=100 \mu \mathrm{m}$. Data represents means \pm SD of six independent experiments. ${ }^{*} P<0.05$ and ${ }^{*} \mathrm{P}<0.01$ vs the control group.

\section{Supplementary Files}

This is a list of supplementary files associated with this preprint. Click to download.

- Graphicalabstract.docx 